\title{
DiscuRsos SOBRE AS TECNOLOGIAS DIGITAIS NA PRÁTICA DOCENTE DE BIOLOGIA: INCLUSÃO E ENFRENTAMENTO
}

\author{
DISCOURSES ABOUT DIGITAL TECHNOLOGIES IN TEACHING PRACTICE IN \\ BIOLOGY: INCLUSION AND CONFRONTATION
}

DOI: $10.23926 /$ RPD.2526-2149.2020.v5.n2.p901-921.id753

\section{Luana de Moraes Margatto \\ Graduada em Ciências \\ Biológicas (UFPR) \\ Professora na Rede \\ Particular de Ensino (PR) \\ E-mail: \\ luanamargatto@gmail.com}

\section{Leandro Siqueira \\ Palcha}

Doutor em Educação

(UFPR)

Professor da Universidade

Federal do Paraná (DTPEN,

PPGE e PPGECM)

E-mail:

leandropalcha@gmail.com
Resumo: As tecnologias digitais se constituem por recursos pedagógicos que adentram a escola e podem auxiliar aos docentes no desenvolvimento da prática educativa, em especial, nos dias de hoje. O objetivo do artigo, portanto, é analisar e compreender os efeitos de sentidos produzidos por professores sobre as tecnologias digitais na prática docente de Biologia. A pesquisa se orientou pelo referencial da Análise de Discurso numa perspectiva qualitativa e contou com a participação de professores da rede pública. Os resultados indicam que há diferentes sentidos da interação das tecnologias digitais no ensino de Biologia, mas que convergem para um efeito de inclusão e enfrentamento das tecnologias digitais na prática docente dos professores. Conclui-se que é pertinente mais debates e integração das tecnologias digitais nos cursos de formação de professores, levando-se em conta que o papel destas tecnologias pode tanto sublimar quanto declinar a partir da interação/interpretação que constrói sobre elas.

Palavras-chave: Análise de discurso. Ensino de Biologia. Formação de professores.

\begin{abstract}
Digital technologies refer to pedagogical resources that enter the school and can assist teachers in the development of educational practice, especially these days. The objective of the article, therefore, is to analyze and understand the effects of meanings produced by teachers on digital technologies in the teaching practice of Biology. The research was guided by the Discourse Analysis framework in a qualitative perspective and had the participation of teachers from public school. The results indicate that there are different meanings of the interaction of digital technologies in the teaching of Biology, but that converge to an effect of inclusion and confrontation of digital technologies in the teaching practice of teachers. It is concluded that more debates and integration of digital technologies in teacher training courses belong, considering that the role of these technologies can both sublimate and decline from the interaction / interpretation that builds on them.
\end{abstract}

Keywords: Discourse analysis. Biology teaching. Teacher education. 


\section{INTRODUÇÃO}

A partir do princípio de que "o discurso é o efeito de sentidos entre os locutores" (ORLANDI, 2013, p. 21), procuramos aqui compreender como se constituem as interações de sentidos entre as tecnologias digitais e a prática docente no ensino de Biologia.

Neste escopo, a linguagem e a sociedade são questões indissociáveis para a constituição simbólica dos sujeitos. A linguagem expressa os sentidos e as interações entre os sujeitos e os objetos do conhecimento em uma perspectiva histórico-social, considerando que "a relação com a sociedade é a relação com a linguagem. Esta, por sua vez, é um fato social. É pela linguagem que o sujeito se constitui e é também pela linguagem que ele elabora sua relação com o grupo" (ORLANDI, 2012, p. 176).

As relações de sentido são, antes, relações sociais e, com isso, trazemos à baila a difícil questão de olhar o campo educativo pelo prisma da linguagem, em determinada conjuntura histórico-social. Em nossa perspectiva:

[...] a linguagem sempre está investida na produção de conhecimento, não apenas como um mero instrumento, mas como parte do próprio processo de constituição do saber, da construção do objeto do conhecimento, da sua compreensão, e da interpretação do que significa o conhecimento produzido no conjunto da produção científica de que participa. (ORLANDI, 2017, p. 241).

Entendemos que os processos de aprendizagem se organizam, restituem e mobilizam diferentes sentidos de acordo com a sociedade. Em sentido ubíquo, a aprendizagem vai além das estruturas físicas da escola e, mesmo dentro dela, estes processos são afetados por um discurso social, mais especificamente, o discurso pedagógico que reflete na formação dos sujeitos e é significado por ela (ORLANDI, 2016).

Ao querermos compreender a educação na contemporaneidade, importa dar atenção para como os recursos pedagógicos são interpretados pelos sujeitos e como são ou não mobilizado por eles, na medida em que:

\footnotetext{
As chamadas 'novas tecnologias' penetram a escola de uma forma pacífica ou às vezes promovendo rupturas, exigindo novos espaços, nova formação dos profissionais, novas relações entre pessoas e destas com o conhecimento, ou seja, provocando mudanças em diversos elementos da cultura escolar. Essas novas tecnologias educativas, geradas em outros contextos, carregam também outra cultura, uma forma particular de produção e de apropriação de saberes. (MARANDINO; SELLES; FERREIRA, 2009, p. 172).
}

Devido a isso, esta pesquisa nos impele a conhecer um pouco mais sobre a influência das relações entre o processo de ensino-aprendizagem e a cultura digital a partir da seguinte proposição investigativa: "Como a prática educativa de biologia vem sendo abordada pelo discurso tecnológico-digital na educação contemporânea?". 
Por isso, analisar o discurso dos professores nos permite compreender como se constroem e desconstroem as relações de sentidos entre os sujeitos e as tecnologias digitais na prática educativa, em função dos espaços, tempos e contextos que propiciam a aprendizagem, ou seja, analisar a tecnologia digital enquanto um objeto simbólico que produz sentidos e "como ele está investido de significância para e por sujeitos” (ORLANDI, 2013, p. 26). Tendo em vista, sobretudo, que: "as tecnologias digitais modificam o ambiente no qual elas estão inseridas, transformando e criando novas relações entre os envolvidos no processo de aprendizagem: professor, estudantes e conteúdos" (BACICH, 2018, p. 137).

De acordo com Arroio (2013, p. 169), atualmente, o professor continua sendo: "a peçachave nessa engrenagem complexa do processo de ensino-aprendizagem, no interesse pelas áreas científicas, pela motivação e prazer em estudar Ciências da Natureza". Isso significa que o professor ainda é um dos principais agentes responsáveis pelo desenvolvimento de uma prática educativa, atravessada por uma gama de discursos que visam a sua formação e capacitação profissional.

Dessa forma, é importante investigar o que revelam os (efeito de) sentidos dos professores sobre a interação entre as tecnologias digitais e as finalidades de sua prática educativa, uma vez que em tempos de tantas e tão rápidas transformações:

[...] precisamos de tempo para olhar e ouvir esses profissionais que certamente têm muito a nos dizer sobre suas experiências em lidar com crianças, adolescentes, jovens e adultos em um cotidiano marcado por conflitos, mas também por expectativas e esperanças. Os saberes dos professores precisam ser melhor conhecidos e valorizados (MONTEIRO, 2005, p. 168).

Por conseguinte, o objetivo da pesquisa reside em compreender os discursos produzidos por professores sobre as tecnologias digitais na prática de ensino de Biologia. Levando em conta que "o analista de discurso não visa interpretar os textos que analisa, mas compreender os processos de significação que estes textos atestam. Detectar os gestos de interpretação que neles se inscrevem" (ORLANDI, 2001, p. 50).

Resta ainda dizer que este estudo pode ser compreendido como um convite para os cursos de formação de professores analisarem os (efeitos de) sentidos que vêm sendo produzidos sobre as tecnologias digitais e que podem ser tomados para reflexão e investigação das práticas docentes da contemporaneidade.

\section{TEORIZAÇÕES SOBRE O ENSINO DE BIOLOGIA E AS TECNOLOGIAS DIGITAIS}


Inúmeros autores têm proposto meios de ensino para abordar o conhecimento biológico nos diferentes espaços educativos (KRASILCHIK, 2016; MARANDINO et al., 2005; CALDEIRA; ARAÚJO, 2009; GÜLLICH; HERMEL, 2017; MARANDINO; SELLES; FERREIRA, 2009). Muitas destes estudos na área de ensino de Biologia trazem pontuações, articulações ou reflexões que evidenciam as relações de sentidos entre o conhecimento científico e a cultura digital.

Faz-se necessário, então, atentarmos para os modos de aprender procurando por trilhas e olhares que permitam aos sujeitos acessar e apropriar-se de um conhecimento biológico contextualizado a sociedade contemporânea. Mais do que nunca, atualmente: “o que está em pauta é uma educação que possa superar os muros da escola, preparando o sujeito para a vida social" (COLELLO, 2017, p. 38).

O currículo do ensino, em uma perspectiva tradicional, quando apenas transmite informações acumuladas visando a repetição e memorização, impede de o aluno integrar o conhecimento à realidade, não vendo sentido nem mesmo conseguindo estabelecer relações de sentido entre o conhecimento científico e o cotidiano. Desse modo, o currículo:

[...] é extenso, fragmentado e desconectado da vida, não pode provocar entusiasmo nos aprendizes contemporâneos. O currículo convencional da escola clássica, baseado em perguntas que têm uma única resposta correta previamente memorizada, não pode inspirar a paixão dos alunos por aprender, investigar, descobrir, aplicar e recriar. A aprendizagem de fragmentos desconexos e pedagogias repetitivas sufoca o desejo de conhecer (GÓMEZ, 2015, p. 42).

Isto mostra, de forma breve, que a escola pode ser lenta em perceber como a situação do mundo externo a sala de aula mudou (e vem mudando) rapidamente, bem como estas mudanças estranhamente levam certo tempo até serem incorporadas pelas práticas docentes de forma harmoniosa.

Pozo e Crespo (2009) argumentam em favor de um modelo de ensino menos tradicional para o Ensino de Ciências, em que a docência se afasta da repetição e transmissão mecânica de informações aos alunos. Assim, sob a ótica construtivista, os autores apostam que é possível modificar a forma de aprendizagem tornando o conhecimento científico mais próximo do cotidiano dos alunos, sendo que as tecnologias podem ser um caminho para isso.

Por nosso lado, desde já, observamos que as tecnologias digitais sejam vistas como materiais escolares utilizados tão somente para despertar o interesse e a motivação dos alunos nas práticas docentes, mas, pelo contrário, pensamo-las como recursos pedagógicos que podem propiciar o aprendizado menos ingênuo e mais reflexivo sobre a realidade, dentro de uma perspectiva educativa, que se ampara pela cultura da sociedade contemporânea. 
A instituição escola, em nosso entender, promove rearranjos discursivos do conhecimento científico que, amparados por diferentes tecnologias, podem contribuir para um aprendizado integrado, amplo e contextualizado à realidade dos alunos. Nessa direção, é importante pensarmos e significarmos a dinâmica que configura a instituição escolar, pois assumimos com Marandino, Selles e Ferreira (2009, p. 23) que:

\begin{abstract}
A instituição escola é o espaço onde se dão os encontros entre professores e alunos, entre currículos, materiais de ensino e processos formativos, os quais nos permitem compreender como as práticas de ensino de Biologia se articulam com os diversos elementos sócio-históricos que as constituem. Isto implica considerar que na escola existem transformações dos conhecimentos biológicos em conhecimentos mais diretamente relacionados às finalidades de ensino, um movimento que ocorre em meio a processos sociais mais específicos.
\end{abstract}

Por este ponto de vista, temos a escola como um entremeio de interpretação de discursos sobre as interações entre conhecimentos científicos, escolares e cotidianos. Em certo sentido, a escola herda uma cultura praticada pela sociedade que, por vezes, cabe aos professores trabalharem-na em sua prática docente, atraindo assim os alunos para as explicações produzidas pela ciência e tecnologia em função da realidade social.

Hoje bem conhecidas, as tecnologias digitais nos permitem representar o "real" do conhecimento científico, a fim de ampliar e aprofundar o aprendizado do aluno no tempo escolar, algo que nem sempre pode ser oferecido pelos recursos pedagógicos tradicionais. Algo que produz um grande efeito no processo formativo do alunado, pois, de fato: "um aluno não conectado e sem domínio digital perde importantes chances de se informar, de acessar materiais muito ricos disponíveis, de se comunicar, de se tornar visível para os demais, de publicar suas ideias e de aumentar sua empregabilidade futura" (MORAN, 2018, p. 11).

A entrada das tecnologias digitais na escola certamente proporciona maiores experiências cognitivas aos alunos, pois a maior parte deles detém certa familiaridade com a cultura digital, e isso pode resultar em êxito nas práticas docentes quando as tecnologias assumem um tom pedagógico. É bem provável, aliás, que diversas propostas didáticas podem ser exploradas para atualizar o aprendizado escolar, desencadeando redes em que permitam aos alunos interagir com os espaços educativos além da sala de aula (SIBILIA, 2012).

Em todo caso, convém refletir sobre a inserção das tecnologias digitais nos contextos e processos de ensino-aprendizagem, a fim de desvendar o grau de interferência que elas produzem nas práticas docentes, ao passo que:

Os estudantes têm habilidades para o uso das tecnologias digitais, mas nem sempre sabem como selecionar, interpretar, organizar e comunicar de forma eficiente os conteúdos que encontram. A mudança de papel do professor nesse processo tem como 
objetivo a busca por estratégias que, incorporadas às aulas consideradas tradicionais, potencializam o papel do estudante em uma postura de construção de conhecimentos, com o uso integrado das tecnologias digitais nesse percurso. (BACICH, 2018, p. 135).

Gómez (2015) assinala que não é indicado apenas disponibilizar informações aos alunos, mas é preciso ensiná-los como usá-las, acessá-las e avaliá-las criticamente para realidade social. Assim, a partir do contato com as tecnologias digitais, a relação ensinoaprendizagem pode ter esse papel de apresentar aos alunos conteúdos que são difíceis de imaginar, aprender e inovar.

Em contrapartida, existem também diferentes barreiras para o ingresso efetivo das tecnologias digitais em sala de aula, tendo em vista que:

Estudos revelam que professores têm usado as tecnologias digitais e sentido mais confiança nessa utilização, mas na maioria das vezes, o uso é restrito à preparação de aulas; poucos deles utilizam esses recursos para trabalhar com os estudantes durante as aulas, como meio de comunicação com os familiares ou, ainda, para estabelecer relação entre o estudo realizado em casa e aquele que é realizado na escola (BACICH, 2018, p. 130).

Em outras palavras, acreditamos que o conhecimento limitado sobre as tecnologias digitais na formação dos professores pode ser a falta de oportunidade para descobrir como otimizar a relação de aprendizagem em sala de aula. Logo, pode haver pouca disposição à compreensão das tecnologias digitais por parte do professor, algo que acontece quando os próprios cursos de Licenciatura abrem poucos espaços para a formação do professor atrelada às vivências de uma cultura digital.

No ensino de Biologia, seja trabalhado na escola ou nos espaços não formais, existem muitas chances de utilizarmos as tecnologias digitais como recursos pedagógicos para atingir os objetivos da aprendizagem. De forma mais proveitosa, as tecnologias podem interferir e produzir diferentes significados ao ensino de Biologia, creditando novas possibilidades na relação deles com a aprendizagem.

Portanto, se quisermos olhar com mais clareza a relação entre a cultura digital e o ensino de Biologia, é pertinente compreender um pouco mais como os professores produzem os (efeitos de) sentidos a respeito das tecnologias digitais em sua atividade cotidiana, pois, assim, é mais fácil compreender o atual funcionamento da escola se partirmos de uma análise de discurso que se constrói pelos diferentes acontecimentos em seus espaços educativos.

Segundo escrevem Carvalho e Gil-Perez (2012, p. 77): “a necessidade de formação permanente surge associada, em um primeiro momento, às próprias carências da formação inicial". E ainda, "muitos dos problemas que devem ser tratados não adquirem sentido até que o professor se depare com eles em sua própria prática". 
A formação e a prática docente podem indicar um discurso a ser desvelado sobre as tecnologias digitais para enriquecer a educação básica. Muitas vezes percebemos que nem todos os professores percebem a relação entre as tecnologias digitais e o ensino ou, até mesmo, simpatiza-se com esta relação, mas não sabe como implementá-la.

\begin{abstract}
As tecnologias digitais trazem inúmeros problemas, desafios, distorções e dependências que devem ser parte do projeto pedagógico de aprendizagem ativa e libertadora. No entanto, esses problemas que as tecnologias trazem não podem ocultar a outra face da moeda: é absurdo educar de costas para um mundo conectado, educar para uma vida bucólica, sustentável e progressista baseada só em tempos e encontros presenciais e atividades analógicas. (MORAN, 2018, p. 11).
\end{abstract}

Ante o exposto, é importante lembrar que existem desafios para o uso das tecnologias digitais, não podemos nos furtar em considerar que elas estão aí e podem contribuir e muito com objetivos de aprendizagem de cada área de conhecimento ou componente curricular. Portanto, nosso intuito de compreender o discurso das tecnologias digitais e seus reflexos na prática docente nos parece ser um caminho possível para entender as interações entre educação e a sociedade contemporânea.

Rosa, Eichler e Catelli (2015) realizaram um estudo para analisar as representações sobre as tecnologias digitais de professores de Química. No estudo, foram entrevistados cinco professores na rede educação no município de Caxias do Sul/RS, sendo que a análise das narrativas docentes permitiu construir duas categorias: Aqui não tem condições e Ajuda a ver o Cotidiano. Os autores concluem que para uma incorporação efetiva das tecnologias a prática, antes, é necessário conjecturar as condições estruturais das escolas, a formação, área de atuação, imaturidade dos estudantes, burocracia interna, bem como as pressões políticas e sociais que interferem no trabalho didático-pedagógico dos professores de Química.

Kenski (2016) destaca que a cultura digital traz uma preocupação aos professores com a atualização de conhecimentos e práticas, ao mesmo tempo em que produz um aumento no número de professores que buscam novos conhecimentos sobre as tecnologias em diferentes contextos e por conta própria.

Atanazio e Leite (2018) desenvolveram uma revisão de literatura, em 14 revistas nacionais na área de ensino de Ciências da Natureza, pesquisando por artigos que abordavam o tema das "tecnologias de informação e comunicação" e "tecnologias digitais de informação e comunicação", entre os anos de 2007 a 2017. Destacam que, para haver uma integração efetiva das tecnologias à prática docente, "é preciso desenvolver estratégias que tenham por objetivo capacitar os professores" (ATANAZIO; LEITE, 2018, p. 99). 
No plano teórico do discurso, sabemos que nenhum (efeito de) sentido é dado anteriormente, mas ele se constitui pela ação dos sujeitos, no espaço da interlocução, assim se quisermos refletir sobre a escola contemporânea, devemos, antes, analisar o discurso que se produz pela escola. Ou seja, o discurso pedagógico que, por definição, é "um dizer institucionalizado, sobre as coisas, que se garante, garantindo a instituição em que se origina e para qual tende" (ORLANDI, 2006, p.23), pode nos oferecer indicativos de como os sentidos sobre as tecnologias digitais vêm sendo formulados e circulam socialmente pela escola.

Pela ótica discursiva que nos filiamos, vemos a necessidade de que introdução das tecnologias digitais na prática de docência seja contemplada por uma perspectiva de formação e não uma capacitação docente. Pois, como endossa Orlandi (2016, p.74), educar não é capacitar, treinar, nem informar, mas dar "condições para que, em seu modo de individuação pelo Estado, o sujeito tenha a formação (conhecimento) necessária para poder constituir-se em uma posição-sujeito que possa discernir, e reconhecer os efeitos de suas práticas na formação social de que faz parte".

Assinalamos que a educação não pode estar desvinculada da sociedade que a produz, assim conhecimento/formação é requisito indissociável para uma educação transformadora. Logo, analisar a constituição do sentido provém dos sujeitos que o elaboram, quando elaboram e do modo como o elaboram, em suma, a história que elaboram e constitui o sentido dentro de uma conjuntura determinada. Na medida em que:

\footnotetext{
A preocupação com a formação docente implica reconhecer a existência de saberes e fazeres pertinentes ao ato de ensinar, e a compreensão de que eles podem ser objeto de ensino-aprendizagem pelos docentes. Esse reconhecimento representa um avanço em relação à perspectiva presente (ainda) no senso comum de que a docência é atividade decorrente de uma vocação, expressão de talento inato que alguns/as privilegiados/as detêm. (MONTEIRO, 2005 p. 153).
}

Até aqui procuramos destacar que as relações discursivas entre as tecnologias digitais e o ensino de Biologia amparam-se pela sociedade que a produz, por isso mesmo analisar o discurso é também uma forma de desvelar os (efeitos de) sentido em uma determinada conjuntura histórico-social-cultural e compreender como ele a vem significando.

\section{ESTRUTURA METOdOlÓGICA DA PESQUISA}

A presente pesquisa faz parte de um estudo mais amplo, realizado com professores de Biologia, atuantes na rede pública de ensino, em uma cidade pequena do interior do Paraná, sendo que cinco professores (um em cada escola da cidade) manifestaram interesse, consentimento e aceitaram participar do estudo em questão. 
Em termos metodológicos, o nível da pesquisa pode ser classificado como pesquisa exploratória que, de acordo com Gil (2010, p. 27), é desenvolvida com “o objetivo de proporcionar visão geral de tipo aproximativo, acerca de determinado fato. Este tipo de pesquisa é realizado especialmente quando o tema escolhido é pouco explorado e torna-se difícil sobre ele formular hipóteses precisas e operacionalizáveis".

A análise dos resultados foi conduzida pelo referencial teórico-metodológico-analítico da Análise de Discurso Francesa (ORLANDI, 2013). Dessa forma, elaboramos um instrumento de pesquisa (questionário) orientado e validado por cinco questões discursivas que procuravam analisar os dizeres dos professores sobre a relação entre as tecnologias digitais e o ensino de Biologia, tendo em mente que:

\begin{abstract}
Os dizeres não são apenas mensagens a serem decodificadas. São efeitos de sentidos que são produzidos em condições determinadas e que estão de alguma forma presentes no modo como se diz, deixando vestígios que o analista de discurso tem de aprender: são pistas que ele aprende a seguir para compreender os sentidos aí produzidos, pondo em relação a dizer com sua exterioridade, suas condições de produção. (ORLANDI, 2013, p. 30).
\end{abstract}

O corpus de análise corresponde às transcrições dos 5 questionários respondidos pelos professores que, para preservar o anonimato na participação da pesquisa, serão representados hipoteticamente pelos seguintes nomes: Charles, Jane, Mathilde, Rachel e Rosalind, condizentes aos primeiros nomes de importantes cientistas que contribuíram para os estudos na área da Biologia.

\title{
4 TeCNOLOGIAS digitais E ENSINO DE BIOLOGIA: DISCURSOS EM ANÁliSE
}

Os resultados da pesquisa foram organizados e discutidos por meio da noção teórica de "recorte", em que as partes da análise são reorganizadas e mantêm relação com o todo discursivo (ORLANDI, 2006). Os recortes são: i) o sentido da tecnologia para os professores; ii) relação do aluno com a tecnologia em sala de aula; e iii) as tecnologias digitais na prática docente do ensino de Biologia.

\subsection{RECORTE I: O SENTIDO DA TECNOLOGIA PARA OS PROFESSORES}

Este recorte apresenta os dizeres dos professores sobre o uso de tecnologias em sala de aula, considerando que a relação professor-tecnologia se constitui: "com o objetivo de aprendizagem já fixado, o professor busca utilizar uma ferramenta tecnológica especifica para potencializar a construção do conhecimento pelo aluno" (BACICH, 2018, p. 138). 
A princípio, no questionário, os professores deveriam indicar se usavam sempre ou frequentemente as tecnologias digitais ou se raramente ou nunca as usavam em suas aulas. Nenhum participante respondeu raramente ou nunca usava as tecnologias digitais.

O professor Charles escreve que sempre usa as tecnologias digitais.

Pela necessidade de inovação no processo de ensino-aprendizagem. Pela questão desafiadora. Dominar essas tecnologias faz parte de dominar novas tendências do processo de ensino-aprendizado. (Charles, grifos nossos).

Segundo ele, as tecnologias digitais fazem parte de um novo modo de ensinar, ou seja, uma nova direção que a educação está tomando, o que nos faz aproximar os seus dizeres de um sentido de inovação. Seus dizeres revelam a importância de dominar as tecnologias digitais a fim de contribuir ativamente com a aprendizagem nas aulas de Biologia.

A professora Rosalind registra que eventualmente usa tecnologias digitais.

A falta de domínio sobre as tecnologias e o fato de ser imigrante, e não nativo digital, atrelado à pouca vontade em dinamizar as aulas. (Rosalind, grifos nossos).

Em seu relato, a docente destaca que usa pouco as tecnologias digitais para dinamizar as suas aulas, em função de ela ser imigrante digital, o que converge seus dizeres, a nosso ver, para um sentido de (falta de) domínio da cultura digital. Isso mostra que uso das tecnologias digitais não se constrói por um domínio implícito, mas que há necessidade de aprender sobre elas também. Ainda, pelas dificuldades da professora, observamos que as tecnologias digitais assumem um efeito periférico em que não são requisitos para que ela se sinta mobilizada a mudar a cultura de suas aulas.

A professora Rachel diz que frequentemente usa as tecnologias digitais.

Costumo usar recursos com multimídias para a exposição de imagens, esquemas $e$ vídeos que ilustrem o conteúdo abordado sempre que possível pensando no aluno que aprende visualmente. (Rachel, grifos nossos).

Nesses dizeres, as tecnologias digitais associam-se com um sentido de visibilidade do conhecimento biológico durante as aulas. Entretanto, as tecnologias digitais assumem um efeito periférico em que elas são usadas pelo professor para que se possa expor o conhecimento e não incluir o aluno no processo de aprendizagem.

O sentido de visibilidade também aparece no relato da professora Jane, quando ela diz que frequentemente usa as tecnologias em suas aulas.

Procuro utilizar o Datashow, para mostrar imagens e vídeos frequentemente e eventualmente solicito o uso do celular para uma pesquisa na internet ou o uso de um aplicativo. (Jane, grifos nossos). 
Jane enfatiza a importância do sentido de visibilidade trazido às tecnologias ao ensino de Biologia, mostrando que conteúdos científicos podem ser trabalhados em suas ações cotidianas. Por outro lado, a professora destaca o papel ativo dos alunos quando solicita que eventualmente façam pesquisas na internet ou usem aplicativos.

A professora Mathilde indica que eventualmente usa as tecnologias digitais.

\begin{abstract}
Devido à dificuldade que encontramos nas escolas públicas em relação ao material disponível, internet de difícil acesso. Também há dificuldades por termos poucas aulas e carência de profissionais auxiliares na preocupação de laboratórios ou aparelhos digitais para manuseio. A gestão da escola procura melhorar sempre para que possamos usufruir melhor das tecnologias. Acredito que o uso das tecnologias pelos alunos dificulta, pois a falta de interesse faz que os mesmos naveguem em outros sites. (Mathilde, grifos nossos).
\end{abstract}

Segundo o relato, as tecnologias digitais se associam com um sentido de dificuldade, desencadeando um duelo para o ensino de Biologia naquela escola. Por estes termos, notamos que as tecnologias assumem um papel periférico na aprendizagem dos alunos, pois a dificuldade de usar a tecnologia ganha força e impede que os docentes e alunos utilizem-nas dentro do contexto escolar.

Em linhas gerais, nota-se que os professores estão preocupados com as tecnologias digitais na sala de aula, como utilizá-las para otimizar a aprendizagem dos alunos. Reconhecem que os recursos tecnológicos podem ser utilizados em sala de aula para auxiliar no processo de ensino-aprendizagem, bem como alguns se sentem desafiados pelos limites impostos pelas condições físico-estruturais das escolas. Os sentidos sobre as tecnologias digitais são acompanhados por um efeito central, quando o papel das tecnologias contribui ativamente para o protagonismo do aluno na aprendizagem, e um efeito periférico em que as tecnologias digitais não salientam o papel protagonista dos alunos e os dizeres reforçam as dificuldades para se trabalhar com elas na escola.

Já em síntese, a análise dos dizeres mostra que os professores estão interessados em assumir o papel de mediadores dessas tecnologias, quando se apresentam abertos à sua utilização e orientação. Por isso é essencial que cada professor ache sua maneira de sentir-se bem, comunicar-se bem, ensinar bem, a fim de ajudar os alunos a aprender melhor. É preciso variar as metodologias, as aulas, o desenvolvimento das atividades, e a forma de avaliar (MORAN, 2007). Por outro, indica que este grupo de professores não possui formação docente para trabalhar com as tecnologias digitais, o que pode dificultar, ou até mesmo impedir, a utilização delas na sala de aula. 


\subsection{RECORTE II: A RELAÇÃo DO ALUNO COM A TECNOLOGIA EM AULA}

Nesse recorte, os professores escrevem sobre a relação dos alunos com as tecnologias digitais. Segundo Bacich (2018, p.138), a relação aluno(s)-tecnologia: "pode ser uma relação de um aluno em um trabalho individualizado ou de diversos estudantes (grupo) com a tecnologia digital" e constitui-se por interações constantes.

O professor Charles faz o seguinte registro.

Muito bom. Aprendo muito com eles. Desperta a curiosidade da maioria. Claro que é preciso observar alguns aspectos que possam comprometer o processo. (Charles, grifos nossos).

Escreve ele que a relação aluno(s)-tecnologia revela um sentido de curiosidade, pois a tecnologia digital chama a atenção dos alunos, mas ressalva que deve haver comprometimento deles para não prejudicar o aprendizado. O relato de Charles indica sua preocupação para envolver cultura digital em suas aulas, desvelando que ao mesmo tempo em que ensina a Biologia ele também a aprende com os alunos, portanto destaca que está conectado ao cotidiano dos alunos e a possibilidade de intercalar as tecnologias em suas aulas.

A professora Rachel diz que os alunos têm domínio sobre as tecnologias.

Eles possuem domínio da tecnologia, porém quando se trata do uso científico eles possuem muitas dificuldades. (Rachel, grifos nossos).

O domínio das tecnologias pelos alunos, segundo a professora, pode ser interpretado como positivo de forma geral, mas, quando se trata do uso específico para o conhecimento científico, sobressai um sentido de dificuldade indicando que falta uma especificidade na relação da tecnologia com a aprendizagem. Essa limitação dos alunos, a nosso ver, pode ser interrogada pela forma como as tecnologias digitais vêm sendo usadas, em sala de aula, para desenvolver o aprendizado do conhecimento científico.

A dificuldade para trabalhar com o conhecimento científico também é observada no depoimento da professora Rosalind.

O aluno obtém informações rápidas e muitas vezes superficiais, e, dependendo da fonte da pesquisa, irrelevantes para conduzir à efetiva aprendizagem. Como a escola é o reflexo da sociedade, a rapidez com que as informações são propagadas constituise em reflexo do artificialismo presente na atualidade. (Rosalind, grifos nossos).

No depoimento, manifesta-se um sentido de superficialidade na relação alunotecnologia-aula, indicando que o contato dos alunos com as tecnologias está acontecendo muito precocemente, porém nem sempre este contato tem o respaldo de fontes confiáveis, ou seja, não auxilia o aluno a uma aprendizagem mais profunda. Pelo revés, a aprendizagem mais profunda poderia ser mobilizada por meio das tecnologias digitais e, além disso, acreditamos também 
que a escola é um reflexo da sociedade, mas também a escola pode ser um reflexo para sociedade, assim incorporar as tecnologias na prática pode contribuir para melhorar o acesso dos alunos nas relações sociais.

A professora Mathilde registra os seguintes dizeres.

Vejo que eles têm uma gama infinita de fonte de pesquisa, conhecimento e suporte. Só que essa interação ocorre somente com grande cobrança porque o aluno não sabe ou não tem interesse em selecionar o conteúdo, classificar e buscar informações gerais e que irão contribuir de maneira positiva para seu aprendizado. (Mathilde, grifos nossos).

Para ela, há uma gama de informações disponíveis para o ensino, mas o aprendizado só acontece a partir de intensas exigências do professor, algo que podem ser interpretadas, por nós, como um sentido de seletividade das informações. Diríamos, por nosso lado, que também há necessidade de uma seleção digital do que se trabalhar na escola, uma vez que nem todos os conteúdos (científicos, sociais, culturais etc.) são mediados em sala, assim uma seleção aparelhada com a mediação didática poderia contribuir com este sentido de seletividade tanto das tecnologias como da abordagem pedagógica para o conteúdo a ser usada em sala de aula.

A professora Jane apresenta o próximo relato.

Os alunos respondem positivamente à construção do conhecimento através das tecnologias melhorando sua disciplina, concentração, capacidade colaborativa, desenvolvem seu raciocínio, autonomia, expressão demonstrando interesse nas atividades informatizadas. (Jane, grifos nossos).

Em nossa perspectiva, o relato de Jane destaca um sentido de construtividade do conhecimento pelo uso de tecnologias, quando os alunos as utilizam para o aprendizado. Mostra que o efeito ativo das tecnologias digitais é positivo em aulas de Biologia, pois desencadeiam uma série contribuições aos processos formativos. De fato, o seu relato vai de encontro com um mundo externo a sala de aula, ressaltando que os alunos mantêm uma expectativa quando as aulas envolvem a cultura digital.

No geral, verifica-se que os professores acreditam no potencial das tecnologias digitais, porém ainda deve acontecer uma mudança do comportamento dos alunos para que esta ferramenta consiga mobilizá-los a aprender o conhecimento biológico. Isso porque, na prática, o professor tem papel fundamental, para toda e qualquer mudança que aconteça, e é a partir dele que os alunos assumirão um posicionamento crítico. É importante que o docente possua uma postura mais aberta, disposta a agrupar novas mudanças da sociedade que influenciam a escola (CASTELLAR, 2013). 


\subsection{RECORTE III: AS TECNOLOGIAS DIGITAIS NA PRÁTICA DOCENTE DE BIOLOGIA}

Neste recorte encontram-se os dizeres dos professores sobre como as tecnologias digitais podem ser utilizadas na prática docente do ensino de Biologia.

O professor Charles escreve o seguinte relato.

Ajuda muito. Demostrar imagens e processos para fenômenos biológicos. Envolver e tornar mais significativo o ensino. (Charles, grifos nossos).

De forma breve, o relato do professor indica que as tecnologias digitais confluem para um sentido de representatividade dos fenômenos biológicos. Sugere, assim, que as tecnologias digitais podem assumir um papel ativo na mediação didática, quando são envolvidas no trabalho docente, por exemplo, para demonstrar as imagens e processos que muitas vezes são abstratos e complexos em uma aprendizagem mais profunda, em relação a representação do real da ciência no contexto da escola.

A professora Rachel afirma que a tecnologia otimiza o seu tempo de aula.

A tecnologia contribuiu imensamente com a Biologia. A possibilidade de visualização de imagens em 3D e animações sobre a constituição das células e de organismos, evita gastarmos tempo fazendo ilustrações. (Rachel, grifos nossos).

No seu relato, os dizeres se vinculam a um sentido de agilidade proporcionado pelas tecnologias digitais no ensino de Biologia, pois com elas não seria necessário fazer ilustrações na lousa, ainda deu como exemplo o conteúdo de células, o qual muitas vezes é difícil de trabalhar por ser um conteúdo considerado "abstrato". De fato, as aulas de Biologia exigem que a mediação didática seja dinâmica e, ao mesmo tempo, eficiente para que os alunos possam aprender e construir as explicações científicas e, nesse sentido, as tecnologias podem ser usadas tendo um efeito ativo no ensino de Biologia.

Rosalind relata que as tecnologias digitais também favorecem o ensino.

Há uma ampla gama de possibilidades no ensino de Biologia, pois a Anatomia, Fisiologia podem ser melhor abordadas, através da projeção de imagens, vídeos, jogos online, sites de consulta extremamente relevantes e interessantes. (Rosalind, grifos nossos).

Nos dizeres da professora, percebemos que as diversas possibilidades oferecidas pelo uso de tecnologias digitais refletem um sentido de versatilidade da Biologia, tendo em vista que algumas disciplinas biológicas podem ser beneficiadas por elas. Isso supõe que as tecnologias podem ser "absorvidas" pelas aulas e assim contribuir para entender as estruturas e funções biológicas, mas que podem ter restrições para o ambiente escolar.

A professora Mathilde produz o seguinte relato. 
Uma relação proveitosa e de forma positiva encontramos um vasto material para conectar o aluno com a prática. A visibilidade de vídeos, figuras e documentos. Também o acesso para a pesquisa de trabalhos e materiais diferenciados. (Mathilde, grifos nossos).

Diz ela que o uso das tecnologias digitais pode contribuir de forma bastante positiva para o aluno estabelecer diferentes relações no ensino de Biologia, o que permite discursivamente sobressair um sentido de praticidade. Já que as tecnologias aliam o conhecimento prático da Biologia e permitem a visualização de imagens, bem como a investigação em fontes e materiais diferenciados para as aulas de Biologia.

A professora Jane escreve o seguinte depoimento.

O professor deve sempre estar atualizado e tornar relevante o processo de ensinoaprendizagem em todas as áreas, incluindo a tecnologia, uma vez que alguns alunos conhecem mais a respeito que o próprio professor. Portanto, trazer a tecnologia para as aulas de Biologia pode ser uma forma de facilitar o aprendizado e instigar a busca pelo conhecimento de uma forma agradável para os alunos. (Jane, grifos nossos).

Pelo relato, as tecnologias digitais desencadeiam um sentido de facilidade para a aprendizagem, quando o professor se encontra atualizado e elas são utilizadas para fomentar a busca do aluno pelo conhecimento, tornando essa busca prazerosa. Os dizeres de Jane enfatizam que os contextos de aprendizagem mudaram e não é apenas na escola em que os alunos podem se apropriar dos conhecimentos biológicos, por isso é importante aproximar as tecnologias do mundo externo à escola, o que denota um efeito ativo das tecnologias para as aulas de Biologia.

Charles escreve que as tecnologias permitem um repertório variado para aulas.

Com certeza. É bom ter um repertório variado. Demonstrar o quanto avança os estudos. As possibilidades de interação e fascínios das descobertas. (Charles, grifos nossos).

Os dizeres da professora apontam que as tecnologias têm um sentido de atualidade dos estudos científicos, o que faz com que os alunos tenham chance de conhecer com o avanço e descobertas dos estudos científicos, sendo assim uma oportunidade de aproximar o aluno do conhecimento científico. Indica que os professores devem interagir também com experiências (repertório) no ensino de Biologia.

A professora Rosalind relata que a tecnologia está em suas aulas.

Para efetuar registro de classe, selecionar questões de portais, para os alunos responderem e atribuir valor aos questionários, baixar vídeo-aulas, slides, preparar aulas, fontes de pesquisa rápida, conduzir os alunos a serem ativos no processo ensino-aprendizagem. (Rosalind, grifos nossos).

Para ela, as tecnologias digitais no ensino de Biologia permitem que os alunos sejam mais participativos, o que demonstra, a nosso ver, um sentido de atividade que as tecnologias podem desencadear ao processo de aprendizagem. Por estes termos, pode-se dizer que quando 
os alunos são envolvidos na tarefa, no contexto de ensino, de produção e aplicação do conhecimento, de modo que se encontrem imersos em projetos de trabalho docente eles podem ser (pro)ativos ao longo do processo de aprendizagem.

Para Rachel a tecnologia na sala de aula pode auxiliar a exposição do conteúdo.

\begin{abstract}
Além da exposição do conteúdo por meio de multimídia, existem aplicativos que auxiliam através do celular. A busca por diferentes formas de abordar o conteúdo como vídeo-aulas, apresentações e plataformas específicas de Biologia auxiliam professores e alunos, além da facilidade de comunicação do grupo. (Rachel, grifos nossos).
\end{abstract}

De acordo com ela, quando se busca trabalhar de diferentes maneiras, como utilizar vídeos, plataformas específicas, entre outros, estas podem ajudar o professor e os alunos. Em outras palavras, tem-se em seu relato um sentido de auxílio que as tecnologias digitais oferecem um apoio ao docente que pode contribuir para o aprendizado de Biologia e também que essas ferramentas facilitam a comunicação em grupo.

A professora Mathilde sugere diversas possibilidades ao uso da tecnologia em aula.

Podemos utilizar com acesso a site de pesquisa, questionários, dúvidas de palavras, artigos e atividades. Também vídeos, slides, figuras, jogos que envolvem conteúdo. Pesquisa para o professor, apresentação e análise de questões do ENEM e vestibulares para a preparação dos alunos. (Mathilde, grifos nossos).

Por meio de seu relato, as tecnologias digitais podem ser usadas de diferentes formas para a preparação de aulas do ensino de Biologia, produzindo um sentido de acessibilidade. Vemos assim que as tecnologias digitais possibilitam aos docentes trabalhar no alcance do conhecimento que desejam ensinar, por meio de diferentes recursos e metodologias de ensino que podem envolver a aplicação dos conteúdos.

A professora Jane apresenta várias possibilidades de usar a tecnologia em aula.

De diversas formas, como simuladores virtuais, jogos virtuais, livros digitalizados, vídeos, planilhas, slides com animações e imagens. (Jane, grifos nossos).

Pelos dizeres de Jane, as tecnologias digitais exprimem um sentido de virtualidade pela pluralidade metodológica que elas permitem para as aulas de Biologia. Isso mostra que é possível modificar a tradição discursiva das aulas de Biologia, por diferentes metodologias de ensino que envolvem a cultura escolar e a cultura digital.

Como observado, os dizeres revelam que a mediação didática pelo docente é fundamental para mostrar aos alunos os critérios de seleção e confirmação de dados; conduzir estratégias de circulação segura e eficiente na sociedade, modos de compartilhar conhecimentos e posturas éticas; gerar oportunidade de analisar situações excepcionais e de solucionar problemas; beneficiar práticas interativas aportadas no consenso e na problematização do saber; 
desenvolver os trabalhos pensados por distintos grupos e estimular o desenvolvimento do espírito crítico (COLELLO, 2017).

As palavras dos professores, de uma forma geral, remetem a diferentes (efeitos de) sentidos em que as tecnologias digitais podem trazer ao serem utilizadas em sala de aula, não necessariamente em um sentido positivo, pois, como vimos, os relatos pressupõem que as tecnologias digitais podem tanto contribuir para o aprendizado dos alunos quanto dificultá-lo quando não há uma estrutura escolar adequada ou uma formação docente para realizar uma abordagem pedagógica das tecnologias em sala de aula.

$\mathrm{Na}$ maioria dos discursos, as tecnologias digitais aparentemente produzem um impacto de inovação para o trabalho pedagógico, o que pode desvelar a associação das tecnologias digitais com um efeito inovador para a prática docente. Inovação que, segundo alguns autores, pode ser garantida por meio de novos recursos tecnológicos; nova estrutura que permite a interação; uma nova estratégia para a formação docente; e, especialmente, a inclusão de novos saberes, sem excluir o conhecimento científico (CAMARGO; DAROS, 2018).

Assim, podemos dizer que desenvolver situações que permitam a participação ativa dos alunos, certamente, pode acarretar em uma alteração da prática, do planejamento e do desenvolvimento de métodos de ensino, visando um aprendizado mais significativo e realmente ligado com as circunstâncias reais. Por esse motivo, a inovação na educação é tão importante. A inovação é uma das formas de transformar a educação (CAMARGO; DAROS, 2018).

Decorrente destas discussões, se pensarmos a educação capaz de transformar a realidade social, antes, é necessário repensarmos a formação de professores (ORLANDI, 2017) para um trabalho com as tecnologias digitais valorizando o papel da produção do conhecimento na escola. Além disso, enquanto território contestado, "a formação do docente certamente precisa abrir espaço para seus próprios atores expressarem seus saberes, suas reflexões e críticas e daí buscarem alternativas e propostas de redefinição" (MONTEIRO, 2005 p. 168).

Convém ainda dizer que os professores conhecem bem as possibilidades e os limites que as tecnologias digitais oferecem, como também identificam seu potencial para utilizá-las em aulas de Biologia. Porém, para que a educação seja inovadora, é necessário antes que os professores assumam também um discurso inovador, assumindo que as tecnologias digitais podem ter um (efeito de) sentido central (ativo) que torne o aluno protagonista da aprendizagem. 


\section{CONSIDERAÇões FINAIS}

O trabalho empreendido, até aqui, demonstra que as tecnologias digitais estão presentes no discurso destes professores de Biologia, por meio de relações de sentidos que envolvem o ensino, os alunos e a prática educativa.

Pela análise de discurso, destacam-se um efeito de inclusão das tecnologias digitais na prática docente, sobressaem sentidos como: a facilitação do aprendizado da Biologia por meio das diversas ferramentas que envolvem imagens, sites, jogos, entre outros, o contato mais próximo com o desenvolvimento da ciência, a promoção de práticas, repostas positivas quanto a utilização das tecnologias digitais, o desdobramento de um ensino ativo, tornar o aluno autônomo para a construção do seu conhecimento. Outrossim, sobressaem-se efeito de enfrentamento para o uso das tecnologias na prática docente que se constituem pelos sentidos de desinteresse de alunos, a falta de domínio do professor, formação continuada deficiente e dificuldade com a estrutura oferecida nas escolas.

Assim posto, entendemos que a prática educativa em biologia englobada pela inclusão de tecnologias digitais precisa de planejamento, tempo e diálogo com a contemporaneidade vivenciada pelos alunos. $\mathrm{O}$ conhecimento sobre a cultura digital, saberes docentes e a prática profissional quando alinhados podem oferecer diferentes possibilidades para o desenvolvimento dos conhecimentos biológicos, bem como favorecer uma aprendizagem profunda e permanente para a vida dos alunos, algo que nem sempre tem ocorrido no contexto educativo.

$\mathrm{Na}$ educação contemporânea, acreditamos que as tecnologias digitais podem e devem ser incorporadas às práticas docentes de forma gradual, prazerosa e com objetivos explícitos de uma aprendizagem mais profunda. Conforme percebemos pelos discursos dos professores há uma gama de possibilidades para articulação ou rearticulação pedagógica das tecnologias digitais, desde as tarefas operacionais do trabalho docente, até a construção de objetos digitais de aprendizagem que podem auxiliar os alunos na compreensão dos conteúdos escolares. Dessa forma, não podemos concordar que elas sejam vislumbradas apenas como fator de motivação ou interesse para o ensino de biologia, no que tange a finalidade da prática educativa.

Não é intenção deste estudo tratar as tecnologias digitais de forma prescritiva, mas compreender os processos de significação que atestam as interações sociais entre elas e a prática docente e, com isso, acreditamos ter cumprido com os objetivos propostos, sendo que por meio da linguagem, os professores manifestam diferentes possibilidades e principalmente desafios que pautam e materializam a cultura digital em sala de aula. 
À guisa de conclusão, defendemos que é pertinente a necessidade de mais debates e de integração destas tecnologias nos cursos de formação de professores, por meio da linguagem, cultura e práticas digitais que se constituem pela contemporaneidade, haja vista o papel das tecnologias digitais na prática docente pode tanto sublimar quanto declinar a partir da interação/interpretação que constrói sobre elas.

\section{REFERÊNCIAS}

ARROIO, Agnaldo. O ensino de Ciências da Natureza para uma sociedade contemporânea. In: CARVALHO, Ana Mara Pessoa de (org.). Formação de professores: múltiplos enfoques. São Paulo: Sarandi, 2013. p. 165-180.

ATANAZIO, Alessandra Maria Cavichia; LEITE, Álvaro Emílio. Tecnologias da Informação e Comunicação (TIC) e a Formação de Professores: tendências de pesquisa. Investigações em Ensino de Ciências, Porto Alegre, v. 2, n. 23, p. 88-103, ago. 2018. Disponível em: https://www.if.ufrgs.br/cref/ojs/index.php/ienci/article/view/947. Acesso em: 17 jan. 2020.

BACICH, Lilian. Formação de professores para o uso de metodologias ativas. In: BACICH, Lilian; MORAN, José (orgs.). Metodologias ativas para uma educação inovadora: uma abordagem prático-teórico. Porto Alegre: Penso, 2018. p. 129-151.

CALDEIRA, Ana Maria de Andrade; ARAÚJO, Elaine Sandra Nicolini de (orgs.). Introdução à didática da Biologia. São Paulo: Escrituras, 2009.

CAMARGO, Fausto; DAROS, Thuinie. A sala de aula inovadora: estratégias pedagógicas para fomentar o aprendizado ativo. Porto Alegre: Penso, 2018.

CARVALHO, Anna Maria Pessoa de; GIL-PEREZ, Daniel. Formação de professores de ciências: tendências e inovações. $10^{\mathrm{a}}$. ed. São Paulo: Cortez, 2012.

CASTELLAR, Sonia Maria Vanzella. Formação docente continuada: possibilidades de melhoria da escola pública. In: CARVALHO, Anna Maria Pessoa de (org.). Formação de professores: Múltiplos Enfoques. São Paulo: Sarandi, 2013. p. 251-266.

COLELLO, Silvia de Mattos Gasparin. A escola e a produção textual: práticas interativas e tecnológicas. São Paulo: Summus, 2017.

GIL, Antônio Carlos. Métodos e técnicas de pesquisa social. $6^{a}$. ed. São Paulo: Atlas, 2010.

GÓMEZ, Angel Ignacio Perez. Educação na era digital: a escola educativa. Porto Alegre: Penso, 2015.

GÜLLICH, Roque Ismael da Costa; HERMEL, Erica do Espírito Santo (org.). Didática da Biologia. Curitiba: Appris, 2017.

KENSKI, Vani Moreira. O Papel do Professor na Sociedade Digital. In: CASTRO, Amélia Domingues de; CARVALHO, Anna Maria Pessoa de (orgs.). Ensinar a ensinar: didática para a escola fundamental e média. São Paulo: Cengage Learning, 2016. p. 95-106. 
KRASILCHIK, Myriam. Prática de ensino de Biologia. 4a . ed. São Paulo: Editora da Universidade de São Paulo, 2016.

MARANDINO. Martha; SELLES, Sandra Escovedo; FERREIRA, Marcia Serra; AMORIM, Antonio Carlos Rodrigues (orgs.). Ensino de Biologia: conhecimentos e valores em disputa. Niterói: EdUFF, 2005.

MARANDINO. Martha; SELLES, Sandra Escovedo; FERREIRA, Marcia Serra; Ensino de Biologia: história e práticas em diferentes espaços educativos. São Paulo: Cortez, 2009.

MONTEIRO, Ana Maria. Formação docente: território contestado. In: MARANDINO. Martha; SELLES, Sandra Escovedo; FERREIRA, Marcia Serra; AMORIM, Antonio Carlos Rodrigues (orgs.). Ensino de Biologia: conhecimentos e valores em disputa. Niterói: EdUFF, 2005. p. 153-170.

MORAN, José Manuel. Ensino e aprendizagem inovadores com tecnologias audiovisuais e telemáticas. In: MORAN, José Manuel; MASSETO, Marcos Tarciso; BEHRENS, Marilda Aparecida (orgs.). Novas tecnologias e mediação pedagógica. $13^{a}$. ed. Campinas: Papirus, 2007. p. 11-66.

MORAN, José. Metodologias ativas para uma aprendizagem mais profunda. In: BACICH, Lilian; MORAN, José (orgs.). Metodologias ativas para uma educação inovadora: uma abordagem prático-teórico. Porto Alegre: Penso, 2018. p. 129-151.

ORLANDI, Eni Puccinelli. Discurso e texto: formação e circulação dos sentidos. Campinas: Pontes, 2001.

ORLANDI, Eni Puccinelli. A Linguagem e seu funcionamento: as formas do discurso. $4^{\mathrm{a}}$. ed. São Paulo: Pontes, 2006.

ORLANDI, Eni Puccinelli. Discurso em análise: sujeito, sentido e ideologia. $2^{\mathrm{a}}$. ed. Campinas: Pontes, 2012.

ORLANDI, Eni Puccinelli. Análise de discurso: princípios e procedimentos. $11^{\mathrm{a}}$. ed. Campinas: Pontes, 2013.

ORLANDI, Eni Puccinelli. Educação e sociedade: o discurso pedagógico entre o conhecimento e a informação. Aled, Campinas, v. 2, n. 16, p.68-80, ago. 2016. Disponível em: https://raled.comunidadaled.org/index.php/raled/article/view/231. Acesso em: 17 jan. 2020 .

ORLANDI, Eni Puccinelli. Eu, tu, ele: discurso e real da história. 2a . ed. Campinas: Pontes: 2017.

POZO, Juan Ignacio; CRESPO, Miguel Ángel Gomez. A aprendizagem e o ensino de Ciências: do conhecimento cotidiano ao conhecimento científico. $5^{\mathrm{a}}$. ed. Porto Alegre: Artmed, 2009.

ROSA, Marcelo Prado Amaral; EICHLER, Marcelo Leandro; CATELLI, Francisco. Quem me salva de ti?: representações docentes sobre a tecnologia digital. Ensaio: Pesquisa em 
Educação em Ciências, v.17, n.1, p. 84-104,2015. Disponível em:

https://periodicos.ufmg.br/index.php/ensaio/article/view/10109. Acesso em: 17 jan.2020.

SIBILIA, Paula. Redes ou paredes: a escola em tempos de dispersão. Rio de Janeiro:

Contraponto, 2012.

Recebido em: 11 de junho de 2020.

Aprovado em: 29 de agosto de 2020. 